\title{
THE DEGREE OF CYBERBULLYING ACCORDING TO GENDER AND SOCIAL ECOLOGY IN THE UNITED ARAB EMIRATES
}

\author{
Khawlah M. AL-TKHAYNEH \\ Assistant Professor, College of Education, Humanities and Social Sciences, \\ Al Ain University, UAE \\ E-Mail: khawlah.altkhayneh@aau.ac.ae
}

\section{Khaled KHAMIS NSER}

Associate Professor, College of Education, Humanities and Social Sciences, Al Ain University, UAE

E-Mail: khaled.nser@aau.ac.ae

\begin{abstract}
This study aims to identify the degree of cyberbullying in a sample of ninth and tenth grade students in Al Ain, United Arab Emirates (UAE) in terms of gender and social ecology variables. The method used was a descriptive analytical approach. The study used the data elicitation tool that includes eight items developed by Buffy and Dianne (2006) to measure the degree of cyberbullying. The researchers added eight additional items based on the students' comprehension level. The results showed that there is a low-impact level of cyberbullying on the tested students in Al Ain/UAE. The results also revealed that there are statistically significant differences at $(\alpha \leq 0.05)$ between the participants who are bullied in terms of gender and social ecology in favor of the students whose parents are of a low educational level and whose mothers are employed. Based on the results, the study concludes with recommendations related to the importance of following social, educational and technical policies to reduce the negative effects of this phenomenon.
\end{abstract}

Key words: Criminology, Social psychology, Cyberbullying, Social ecology, Gender, UAE. 


\section{Introduction}

Since the end of the twentieth century, the dominance of globalization and modernization has caused great concerns. As a result, various governments are working to handle the challenges associated with social changes, especially those related to the primary socio-educational institutions, i.e. family and school. Globalization is not concerned with these governments' cultural specificities. That is why there is a need to establish a state of balance to limit the negative effects created by modernization. Otherwise, if this balance is not established, the social challenges accompanying modernity would most certainly increase. Every now and then, various phenomena emerge and are described as one of the scientific and technological consequences that accompany social changes in all of its aspects. The juvenile delinquency phenomena which include traditional bullying, cyberbullying, violence and school dropouts are considered to be one of the most common social changes resulting from modernization. This juvenile delinquency is regarded as the most dangerous phenomenon since it has a huge impact on the society as a whole. This is because juveniles represent the future of any society and are thus the cornerstone of a strong society. Cyberbullying has turned to be a global nightmare since it spreads and affects all components and structures of the society, i.e. it does not only affect the bullied or victimized children, but all society groups. Although most bullying acts do occur off the educational institutions' campus, their consequences are brought to the school campus wreaking havoc on the students within. What makes cyberbullying dangerous is that it is connected to technology and the virtual world, so its residual effects are still there without the need of face-to-face interaction.

Schneider, Donell, Stuve \& Coulter (2012) indicated that suicide rates among students have increased significantly, with most of the increase being caused by cyberbullying. Another study conducted by Lenhart, Madden, Macgill \& Smith (2007) confirmed that teenagers surf the internet and social media on a daily basis. Accordingly, school students who use these means could encounter personal attacks and harassment every day and the negative impacts left on them would make their school experience intolerable. As a result of these negative effects of cyberbullying, cybercrimes have been criminalized in the UAE under the Federal Law No. 5 of 2012 and its amendments in 2016. In particular, using the internet to invade the privacy of another person, photographing people and publishing information, statements or news about them, audio- or video- recording of any communication or conversations are all punishable by UAE law. This punishment includes imprisonment and/or a fine which ranges between AED 500,000 and AED 2,000, 000 based on the severity of the violation (The United Arab Emirates Government Portal, 2020). 
The significance of this study can be traced back to the importance of the topic it deals with. The topic is a new one that developed due to the advent of new technology. Being able to provide the reader with a theoretical framework on cyberbullying clearly reflects the importance of such study. This study can be used to direct individuals, particularly students, to the means of dealing with modern communication technologies. Furthermore, the study aims to apply scientific theories in designing the methodology and analyzing its data. Accordingly, the findings will help social and economic planners, sociolinguists, decision makers and civil society organizations to develop suitable social and legal policies to reduce the effects of cyberbullying. Such results can be extended to new public and private sectors and other relevant educational institutions. These results would help other researchers in finding remedial and preventative measures to put an end to such an increasingly alarming phenomenon. The factors that are taken into account to examine the degree of cyberbullying among school students in the UAE include the participants' gender, parents' educational qualification and the mother's employment. It is hypothesized that such factors can have an effect on the degree of cyberbullying in the UAE context based on the researchers' observation. Accordingly, the study aims to address the following research questions:

1. What is the degree of cyberbullying among a sample of ninth and tenth grade students in Al- Ain, UAE?

2. Are there statistically significant at $(\alpha \leq 0.05)$ differences according to participants' gender?

3. Are there statistically significant at $(\alpha \leq 0.05)$ differences according to social ecology states such as the parents' educational qualification and the mothers' job status?

\section{Theoretical Background}

\subsection{What is cyberbullying?}

Buffy \& Dianne (2009, p. 2) defined cyberbullying as "online harassment using social media means by which the cyberbully tries to find ways that can make the victim feel threatened and nervous." Cyberbullying is different from traditional bullying in that it is not specific to a certain time or place. In the case of cyberbullying, the bully is not sentenced and punished as in traditional bullying. The social media means allow the cyberbully to identify the location of the person he is trying to attack and that makes that person an easy target (Trolley, Hanel \& Shields, 2006).

In this study, social ecology is defined as the social environment and the psychological, spatial and social relations that link individuals and groups with each other. In addition, it is related to bidirectional effects between individuals 
and the environment they live in. Such an environment does not necessarily involve a physical space. However, it is the social space with all its aspects that is concerned with the spatial and temporal distributions of individuals and groups under certain circumstances. Furthermore, such environment is concerned with the factors responsible for the changes of these distributions.

The social ecology is concerned with the indirect relationships among groups in different urban and industrial areas and the types of such relations. Moreover, it focuses on the important role of the norms and traditions in controlling the individual's social behavior.

\subsection{Cyberbullying from the social psychology perspective}

Sutherland \& Cressey (1970) studied the deviance phenomenon among children at two levels. The first level is related to the individual's psychological aspects, whereas the second level focuses on the society in which the individual lives. The individual's psychology depends on his family, since deviancy is a social phenomenon that happens due to certain family conditions the deviant might face. For instance, when there is a member in the family who tends to be a bad role model due to his deviant actions, he would be a major reason behind the deviant behavior of another member in the family, since the controlling authority in this social institution (home) is not functioning properly. In this case, such control authority is meant to be the mother or father. Sutherland \& Cressey (1970) proposed the main factors that enhance the child to perform a delinquent behavior such as bullying that were introduced in the Differential Association Theory to be as follows:

1. The child who encounter deviant attitudes, situations and bad behavioral models regularly at home would learn and acquire such deviant behavioral patterns.

2. The residential location is a major influencing factor that determines the behavioral patterns the child would interact with. If the child lives in a delinquent environment, the possibility of being affected by the deviant models would increase a lot and vice versa.

3. When a child commits a bad behavior and is kicked out of the house that would isolate him from his family and would not allow him to practice his role as a part of a unified group. The important issue is that isolating the child from his family would increase the possibility of acquiring deviant behaviors.

4. When the parents fail in the process of social upbringing, the child would fail to distinguish between the accepted behaviors and the rejected ones. 
The degree of cyberbullying according to gender and social ecology...

5. If the child is not used to being obedient at home especially during the process of social upbringing, that would lead him to refuse any form of authority.

6. Stress and emotional instabilities inside the family play an important role and have an effective impact on children. These instabilities would influence on the child's behaviors. For instance, the deviant behavior is an expected reaction when the family is a dysfunctional and broken one.

(Sutherland \& Cressey, 1970, pp. 212-214)

Freud assumed that this phenomenon and other similar phenomena are the result of painful experiences the child encountered in the early stages of his life in a form of an aggressive behavior (Kline, 2013). However, according to the behaviorism theory, the repetitive reinforcement is the main reason behind such phenomenon. When children try to get whatever they want, with their actions being reinforced by their parents, they will tend to repeat such acts whenever they want something. That is why the parents need to reinforce the act at first, then punish to restrain the rejected behavior making sure that it will not be repeated again. On the other hand, the cognitive theory views the bullying behavior as a realization the bullies attempt to impose themselves and their abilities on their surroundings. This can be done through exploring the surrounding environment and the behavior of the surrounding individuals, then comparing the two behaviors, theirs and the other's. In the end, they would find themselves able to lead and control individuals who are weaker than they are (Kline, 2013).

\subsection{Previous Studies}

Skitka (1980) investigated the impact of social facilities on the juvenile delinquents. The sample included 131 male and female offenders in the juvenile prison in a Midwestern city in the United States. Using statistical reports, it was found that there is a relationship between social facilities and the gravity of the crime.

Lowry, Zhang, Wang \& Siponen (2016) conducted a study after the striking increase in the use of social media which has led to changes in the traditional social structures and shifts the nature and means of the interpersonal communication from physical to cyber. While these means may be used to fulfill positive purposes such as the potential need for communication, they can also be used for negative purposes, such as cyberbullying that is the main focus of the paper. This paper aims to understand why individuals, mostly adolescents, participate in cyberbullying and to fill in the gaps of how the means of technology can used to hinder cyberbullying and why people are socialized to engage in cyberbullying. The researchers modified Akers' model of social 
structure and social learning and proposed the social media cyberbullying model (SMCBM). Akers' model presents a general theory for crime and deviance in relation to the physical world. However, the SMCBM addressed anonymity as a key variable to account for the Information Technology (IT) means. The model was tested on 1,003 adults engaged in cyberbullying. The researchers concluded that the anonymous use of the social media means facilitated the process of cyberbullying. The study introduced new directions for cyberbullying research and implications for anti-cyberbullying practices.

Brochu (2017) conducted a study on students at Zayed University in the United Arab Emirates which introduced a better understanding of the effects of cyberbullying on the female undergraduates. The study was quantitative, including 655 participants, 95\% (592 participant) of whom were users of social media out of which $47.39 \%$ (291 users) suffered from online harassment while $95 \%$ of the participants hoped to have a pleasant and respectful online experience.

Ortega, Buelga, Cava \& Torralba (2017) analyzed the variations among students facing cyberbullying and their attitudes toward the institutional authority. Furthermore, the study tried to investigate the ways in which the students participate in the violent school behaviors whether directly or indirectly. The focus of the paper was the gender as a variable affecting all the previously mentioned factors. The study sample included 1062 secondary students of both genders, between 12 and 18 years old. The results of the multivariable analysis show the major effects of the group and gender variables on the cyberbullying acts. It was found that the severe cyberbullies greatly reject the institutional authority. In addition, they regularly tend to violate norms. Furthermore, they practice direct and rational violent behaviors toward their peers. The study concluded that males more than females tend to transgress the social norms and to perform direct violent behaviors such as the direct confrontation of the victims. By conducting regression analysis, it was revealed that all these variables predict for cyberbullying.

Almakanin, Younis \& Alhiary (2018) conducted a study on the degrees of cyberbullying among a sample of students with emotional and behavioral disorders in Zarqa, Jordan. The study aimed at investigating the existence of any differences in the degrees of bullying due to gender and age. The sample consisted of 117 male and female students. The results indicated high degrees of cyberbullying among students, with a mean of 3.77 out of 4. Additionally, statistically significant differences were found between male and female students in favor of male students, favoring students older than 14 years.

In the UAE context, Alomosh, Alrahoomi, Alshamsi, \& Alani (2019) examined bullying among school students on the UAE focusing on the pervasiveness and form of this phenomenon. Based on a questionnaire which 
was distributed to 1,309 students of both genders, the results revealed that $33.3 \%$ of the respondents were involved in bullying acts with $14.2 \%$ being the causer of the act, while $19.1 \%$ were the affected party. These bullying incidents took place mostly on school premises and included insults followed by cyberbullying. The reasons for bullying were mostly the smaller size and the young age of a student. The results also showed that $78.4 \%$ of the victimized student knows the identity of his/her bully. It was also found that teachers are aware of such bullying incidents. The study concluded with some recommendation to limit the effect of this phenomenon such as a stronger or stricter school administration (Alomosh, et al. 2019).

In another study, Abaido (2020) investigated the nature, venues and prevalence of cyberbullying among university students in the UAE. The motivation for conducting the study stemmed from the increasing negative effects of cyberbullying and the scarcity of research of this phenomenon in Arab communities. The results revealed that $91 \%$ of the 200 respondents indicated that cyberbullying takes place on social media websites such as Instagram (55.5\%) and Facebook (38\%). The study recommended stipulating more rigorous regulations, legal actions, and smartphone application to reduce the impact of this phenomenon.

Rehim, Al-Tkhayneh and Al. Shams (2020: 218) found that there at least five reasons that lead to cyberbullying. First, the absence of the parents' supervision. Second, the negative impact of media on children. Third, low level of adherence to ethics and values in our society. Fourth, the prevalence of violence. Fifth, cyberbullying itself, since the bully himself can be a victim of another bully. Furthermore, it was found that cyberbullying might lead to mental disorders such as depression, frustration and stress, social problems like isolation, lack of relations and academic troubles as poor concentration that affects the academic performance.

\section{Methodology}

This study depends on the descriptive analytical approach to achieve its purposes. It aims to determine the level of cyberbullying that affects a sample of middle school students in the $9^{\text {th }}$ and $10^{\text {th }}$ grades in $\mathrm{Al}$ Ain, UAE in relation to gender and social ecology.

\subsection{The study sample and population}

The study sample included middle school students in the $9^{\text {th }}$ and $10^{\text {th }}$ grades in four public and private schools in $\mathrm{Al}$ Ain in the UAE. The schools were selected using simple-random sampling. Consent forms were obtained from the participants' guardians prior to conducting the study. The study instrument was applied on the sample following certain systematic steps: 
First: In order to make sure that the sample represents the whole target audience, a random pilot sample of 30 students in an Al Adel school was chosen, using simple random sampling techniques. The purpose was to identify any challenges that may arise later and to determine the appropriate statistical procedures to examine the psychometric properties in determining the validity and reliability of the study instrument.

Second: Identifying the main sample of the study and its numerical distribution which amounted to 300 students including both male and female.

Third: After making sure that the study instrument was ready to be applied to the sample, the questionnaire was distributed to the 300 students in their schools. Two hundred forty-four questionnaires were returned, 56 wereexcluded for failing to meet the questionnaire's requirements. The final sample included 244 students, including both male and female.

Table 1 . The distribution of the study sample according to their qualitative and functional characteristics

\begin{tabular}{|c|c|c|c|}
\hline Variable & Category & Frequency & Percentage $(\%)$ \\
\hline \multirow[t]{2}{*}{ Gender } & male & 100 & $41 \%$ \\
\hline & female & 144 & $59 \%$ \\
\hline \multirow{3}{*}{$\begin{array}{c}\text { Parents' educational } \\
\text { level } \\
\text { (university graduate) }\end{array}$} & both & 162 & $67 \%$ \\
\hline & one of them & 50 & $20 \%$ \\
\hline & none of them & 32 & $13 \%$ \\
\hline \multirow[t]{2}{*}{ Mother's job status } & working & 145 & $59 \%$ \\
\hline & not working & 99 & $41 \%$ \\
\hline \multirow{3}{*}{$\begin{array}{l}\text { Family's monthly } \\
\text { income } \\
\text { (AED) }\end{array}$} & $\begin{array}{c}\text { less than } \\
10000\end{array}$ & 25 & $10 \%$ \\
\hline & $\begin{array}{c}10000- \\
20000\end{array}$ & 74 & $31 \%$ \\
\hline & $\begin{array}{c}\text { more than } \\
20000\end{array}$ & 145 & $59 \%$ \\
\hline
\end{tabular}

Table 1 shows that $41 \%$ of the sample is of males and $59 \%$ is of females. According to the academic qualification of the parents, it was found that $67 \%$ are of both are educated, $20 \%$ of one of them is educated and $13 \%$ of none of them is educated. In relation to the monthly income variable, $10 \%$ of the sample gets less than 10000 AED per month, 31\% gets 10000-20000 AED monthly and $59 \%$ gets more than 20000 AED in one month. Regarding the mother's job status, the students who have working mothers represents $59 \%$ of the sample and $41 \%$ are of students whose mothers are not working.

\subsection{The study instrument}


The degree of cyberbullying according to gender and social ecology...

The procedures for verifying the validity and reliability of the study instrument were as follows:

1. The validity of the study instrument: The researchers checked the validity of the study instrument using two methods:

A. The face validity: In order to verify the face validity of the study instrument the study relied on the agreement between arbitrators, thus making some changes in the instrument. It was introduced to six professional arbitrators from among faculty members at $\mathrm{Al}$ Ain University and UAEU University. They were asked to arbitrate the validity of the instrument by determining the impulsivity of the study items and their relatedness with the axis. They then stated their opinion on whether the axis added by the researchers were suitable and sufficient to measure the degree of cyberbullying. Due to the fact that the scale had been edited, it needed to be revised by specialized referees to judge its validity.

B. The content validity of the study instrument: In order to verify the content validity of the study instrument, the questionnaire was applied to a pilot sample. They were asked to answer the questionnaire items. After returning the questionnaires, their validity and reliability were verified using Pearson correlation coefficient between the items in each axis and the total score of the axis. The results revealed that the correlation coefficients ranged between (0.527-0.884).

2. The reliability of the study instrument: The reliability of the study instrument was proved by measuring the stability coefficient (Pearson correlation coefficient) using the test and re-test method and applying it on the pilot sample. There was a period of two weeks between the first test and the second test. Furthermore, the study reliability was verified using Cronbach alpha coefficient. The value of reliability coefficient for the axes of the study and the instrument were as shown in Table 2.

Table 2. The reliability coefficient (Pearson correlation and Cronbach alpha) for the axes of the study instrument and the whole instrument

\begin{tabular}{|c|c|c|c|}
\hline Axis & Number of items & Cronbach alpha & $\begin{array}{c}\text { Pearson } \\
\text { correlation }\end{array}$ \\
\hline total & 16 & 0.755 & $0.67 * *$ \\
\hline
\end{tabular}

**statistically significant at $(\alpha \leq 0.01)$

Table 2 shows that the total Pearson correlation coefficient of the study instrument between the two tests was 0.67 .

\section{Results and discussion}


To answer the first question 'What is the degree of cyberbullying among a sample of ninth and tenth grade students in Al Ain/ UAE?', the deviation standard values and the significance level of the sample's answers were calculated using the edited scale designed by Buffy \& Dianne (2009) to measure the degree of cyberbullying that Al Ain middle school students might face. The test instrument adopted was that of the Akers' model of social structure and social learning, yet eight additional items were proposed by the researchers to establish the social media cyberbullying model (SMCBM). The total 16 items were then arranged in a descending manner according to the level as shown in Table 3.

Table 3. The means, standard deviations and the level of responses to the study items

\begin{tabular}{|c|c|c|c|c|c|}
\hline $\begin{array}{c}\text { Item } \\
\text { number }\end{array}$ & Items & Mean & $\begin{array}{l}\text { Standard } \\
\text { deviation }\end{array}$ & $\begin{array}{l}\text { Order } \\
\text { accordin } \\
\mathrm{g} \text { to } \\
\text { significa } \\
\mathrm{nt}\end{array}$ & $\begin{array}{l}\text { Sig. } \\
\text { level }\end{array}$ \\
\hline 1 & $\begin{array}{l}\text { I express my anger via virtual } \\
\text { texts }\end{array}$ & 2.33 & 0.937 & 6 & medium \\
\hline 2 & $\begin{array}{l}\text { I include rude and vulgar } \\
\text { words in the messages } \\
\text { directed at my classmates on } \\
\text { internet and social media } \\
\text { means }\end{array}$ & 1.78 & 0.737 & 8 & low \\
\hline 3 & $\begin{array}{l}\text { I repeatedly send offensive } \\
\text { and ill-considered messages to } \\
\text { some students via internet and } \\
\text { social media means }\end{array}$ & 1.57 & 0.753 & 10 & low \\
\hline 4 & $\begin{array}{l}\text { I keep sending virtual texts } \\
\text { till I get a response }\end{array}$ & 2.36 & 1.089 & 3 & medium \\
\hline 5 & $\begin{array}{l}\text { When bored I send virtual } \\
\text { texts to the students to bother } \\
\text { them and to have fun myself }\end{array}$ & 1.91 & 0.898 & 7 & low \\
\hline 6 & $\begin{array}{l}\text { I threat others that I would } \\
\text { harm them if they did not } \\
\text { response nor interact with my } \\
\text { messages }\end{array}$ & 1.18 & 0.585 & 16 & low \\
\hline 7 & $\begin{array}{l}\text { I send virtual texts with } \\
\text { incorrect data and rumors that } \\
\text { might harm the students }\end{array}$ & 1.65 & 0.784 & 9 & low \\
\hline 8 & $\begin{array}{l}\text { I try to ruin the reputation of } \\
\text { some students by posting }\end{array}$ & 1.48 & 0.693 & 11 & low \\
\hline
\end{tabular}


The degree of cyberbullying according to gender and social ecology...

\begin{tabular}{|c|c|c|c|c|c|}
\hline & $\begin{array}{l}\text { certain virtual texts on social } \\
\text { media platforms }\end{array}$ & & & & \\
\hline 9 & $\begin{array}{l}\text { I impersonate a fake } \\
\text { personality on social media } \\
\text { means }\end{array}$ & 2.33 & 1.011 & 4 & medium \\
\hline 10 & $\begin{array}{l}\text { I post my classmates private, } \\
\text { embarrassing and secret } \\
\text { information on my private } \\
\text { account }\end{array}$ & 1.42 & 0.665 & 13 & low \\
\hline 11 & $\begin{array}{l}\text { I use photos and videos to } \\
\text { threat others and ruin their } \\
\text { reputation }\end{array}$ & 1.40 & 0.675 & 14 & low \\
\hline 12 & $\begin{array}{l}\text { I am keen to keep updated } \\
\text { with the latest techniques and } \\
\text { technologies to use them for } \\
\text { harming others }\end{array}$ & 1.31 & 0.616 & 15 & low \\
\hline 13 & $\begin{array}{l}\text { I block some of my classmates } \\
\text { for no reason }\end{array}$ & 2.33 & 0.995 & 5 & medium \\
\hline 14 & $\begin{array}{l}\text { I keep stalking the private } \\
\text { account of some students to } \\
\text { threaten them later }\end{array}$ & 1.46 & 0.668 & 12 & low \\
\hline 15 & $\begin{array}{l}\text { I block all the inactive } \\
\text { followers on my account }\end{array}$ & 3.08 & 1.011 & 2 & medium \\
\hline 16 & $\begin{array}{l}\text { The inactive followers on my } \\
\text { account tease me }\end{array}$ & 3.38 & 1.115 & 1 & low \\
\hline Total & & 1.94 & 0.86 & - & low \\
\hline
\end{tabular}

The results shown in Table 3 resemble the answers of the study sample that reflects the students' level of cyberbullying in Al Ain. It was clear that the total of all the responses were of medium-low level with a value of 1.94 as mean and a standard deviation of 0.86 . Such results indicate that the study sample has a medium-low level of cyberbullying which is expected since the students are normal with no behavioral, psychiatric nor emotional disorders. Such an assumption was made after checking the students' data according to the demographic variables. Whereas certain responses are of medium level, none of them is of a high level. The responders' levels and their order as shown on Table 3 can be clarified and classified as follows:

1- Six axis in the instrument of the cyberbullying level among the study sample of students in $\mathrm{Al}$ Ain are of a medium level. These are items 1, $4,9,13,15$ and 16 in Table 3 with mean that ranges between (2.333.38). Item 16, which says "the inactive followers on my account tease me", gets the highest level with 3.38 as a mean value. This is logical 
since students at this age are not mature and are too quick when it comes to decision making and judging people. Furthermore, their ego dominates their superego according to Freud's theory in psychology. On the other hand, item 6, that says "I threaten others that I would harm them if they did not response nor interact with my messages", is the lowest in level with a mean of 1.18. Such result reflects the values, e.g. tolerance, respect, kindness etc. Emirati children are raised with and proves the safe and secure social environment in which the Emirati community lives. In addition, they are normal individuals with no behavioral, psychiatric nor emotional disorders. Accordingly, such result seems to be perfectly reasonable.

2- Items 2, 3, 5, 6, 7, 8, 10, 11, 12 and 14 in Table 3 have mean that ranges between (1.18-1.91). This is an indication on the convergence of the sample's views in relation to the axis on the scale.

Are there statistically significant $(\alpha \leq 0.05)$ differences according to participants' gender?

Table 4. The results of T-test in relation to gender of two separate samples to figure the diversity between the standard deviation values among the sample's individuals in relation to the level of cyberbullying

\begin{tabular}{|c|c|c|c|c|c|}
\hline Gender & Number & Mean & $\begin{array}{c}\text { Standard } \\
\text { deviation }\end{array}$ & T-value & Sig. level \\
\cline { 1 - 4 } Male & 100 & 2.32 & 0.382 & \multirow{2}{*}{10.843} & .00 \\
\hline Female & 144 & 1.76 & 0.221 & 10.843 \\
\hline
\end{tabular}

In order to answer this question, the researchers performed the (T) test of variance analysis on the two groups separately to reach the differences in the means values among the sample's individuals in relation to the degree of cyberbullying based on the gender. As seen in Table 4, it is clear that there are statistically significant at $(\alpha \leq 0.05)$ in favor of the males. T-value is 10.843 at $(\alpha \leq 0.000)$ which is a statically significant value.

Such results could be regarded as reasonable and expected due to the customs and traditions of the UAE society that control and restrict females' behaviors more than that of males. In addition to the high likelihood of being victims of cyberbullying (Brochu, 2017), females are much more cautious when dealing with social media. Furthermore, females are more frightened of establishing strange relations online due to their restricted socialization. Such an assumption is congruent with the results of Almakanin, Younis \& Alhiary (2018). It is worth noting that the results of this study agree with the results of Ortega, Buelga, Cava \& Torralba's (2017) study as well.

Are there statistically significant differences at the level $(\alpha \leq 0.05)$ in the respondents' answers attributed to the variables of the parents' educational 
The degree of cyberbullying according to gender and social ecology...

qualification and the mother's job status? In order to answer this question, the researchers performed the test of variance analysis, and the results are shown in Table 5.

Table 5. The analysis of variance test according the degree of cyberbullying among the participants in Al-Ain city in relation to the variable of social ecology

\begin{tabular}{|l|c|c|c|c|c|}
\hline Source of variance & $\begin{array}{c}\text { Total } \\
\text { square } \\
\text { s }\end{array}$ & $\begin{array}{c}\text { Degree of } \\
\text { freedom }\end{array}$ & $\begin{array}{c}\text { Mean } \\
\text { squares }\end{array}$ & $\begin{array}{c}\mathrm{F} \\
\text { value }\end{array}$ & $\begin{array}{c}\text { Sig. } \\
\text { leve } \\
1\end{array}$ \\
\hline $\begin{array}{l}\text { The parents' educational } \\
\text { qualification }\end{array}$ & 0.22 & 1 & 0.21 & $15.49 *$ & 0.00 \\
\hline $\begin{array}{l}\text { The mother's } \\
\text { employment states }\end{array}$ & 0.065 & 1 & 0.07 & $3.79 *$ & 0.02 \\
\hline degree of error & 4.283 & 278 & 0.01 & - & - \\
\hline Total & 11.288 & 303 & - & - & - \\
\hline
\end{tabular}

*statistically significant at $(\alpha \leq 0.05)$

As seen in Table 5, it is clear that there are statistically significant differences between the mean responses for the study sample individuals towards the degree of cyberbullying due to the variable of the parents' educational qualification and the mother's job status. According to the first variable, the calculated f-value was (15.49), which is statistically significant at the level $(\alpha \leq 0.05)$. In order to determine the statistical differences between the mean 16 responses, the researchers performed LSD test for post comparisons between the means as in Table 6.

Table 6. LSD test results for testing the diversity between the participants' responses in relation to the variable of parents' qualifications

\begin{tabular}{|l|c|c|c|c|}
\hline $\begin{array}{l}\text { The parents } \\
\text { educational } \\
\text { qualification mean } \$\end{array}$ & & \multicolumn{3}{|c|}{ The difference between means } \\
\cline { 3 - 5 } & 2.672 & - & -0.090 & $*_{-} 0.385$ \\
\hline $\begin{array}{l}\text { Both of } \\
\text { them }\end{array}$ & 2.702 & - & - & -0.295 \\
\hline One of them & 2.990 & & - & - \\
\hline $\begin{array}{l}\text { None of } \\
\text { them }\end{array}$ & & & & One of them \\
\hline
\end{tabular}

Table 6 demonstrates that there are statistically significant differences in favor of those responders neither of whose as parent's were educational qualified, where the mean for their responses was $(0.385)$ which is statistically significant at $(\alpha \leq 0.05)$. This result can be attributed to the lack of awareness among the 
parents who are not university graduates about the technology risks on their children, particularly in case of excessive use. Furthermore, these parents are not familiar with the updated scientific knowledge, so they are able to direct their children to the correct ways of dealing with means of technology and how dangerous it can be. That would lead the children to the track of cyberbullying as victims or cyberbullies themselves (Skitka, 1980).

Table 7. LSD test results for testing the mean for the responses of the study sample according to the social ecology regarding the mother's job status variable

\begin{tabular}{|c|c|c|c|c|}
\hline Variable & Category & Number & Mean & $\begin{array}{c}\text { The difference } \\
\text { between means }\end{array}$ \\
\hline $\begin{array}{c}\text { The mother's job } \\
\text { status }\end{array}$ & $\begin{array}{c}\text { not } \\
\text { working }\end{array}$ & 145 & 1.427 & -0.335 \\
\cline { 2 - 4 } & working & 99 & 1.782 & \\
\hline
\end{tabular}

Table 7 shows that the differences are in favor of the students of whose mothers are working, where the mean of their responses was higher than that of the students whose mothers are not working. The difference between the means was $(0.335)$ and it is statistically significant at the level $(\alpha \leq 0.05)$. This result is logically accepted, since working mothers are under an enormous workload with long working hours which can affect negatively on their ability to monitor and guide the behaviors of their children. Additionally, domestic servants allow the children they supervise to use the technology means for long periods of time with the absence of real and direct supervision by the mothers. All of that make them an easy victims of cyberbullying. Such result goes with Lacassagne's theory of social milieu (Becker \& Wetzell, 2006). That is, according to Lacassagne, crime results from the interaction between the individual and his social environment. That is, this environment acts as a trigger that activates a dormant criminal nature which is acquired hereditarily. As such, to set off criminal behavior, the right combination of conditions is needed (Becker \& Wetzell, 2006). Many studies support the views of Lacassagne's in his theory as the study of Sumayya (2006). 
The degree of cyberbullying according to gender and social ecology...

\section{Conclusion and recommendations}

The current study employed a descriptive analytical approach on a sample of 244 ninth and tenth graders from both genders in the city of Al Ain in the UAE to examine the degree of cyberbullying. The data elicitation tool adopted was the eight items questionnaire of Buffy \& Dianne (2006), with eight other items being added by the researchers according to the students' comprehension level. The results revealed that there are statistically significant differences at $(\alpha \leq 0.05)$ pertaining to the degree of cyberbullying among the study sample in terms of the variable of gender in favor of males. Another statistically significant difference was detected related to the variable of mother's employment status in favor of the students whose mothers are employed. In relation to the parents' educational level, statistically significant differences were revealed in favor of the students whose parents have a low educational level. The study recommends the need for social policies that aim to control and reduce this phenomenon which negatively affects young children. This can be done by applying such policies using deterrent technological techniques and by stipulating stricter penalties to prevent this phenomenon. Most importantly, the need for preventive measures such as training workshops conducted by the community police responsible for the primary educational institutions of the family and the school. The study also calls for the need to facilitate researchers' task in collecting the needed data for their research papers by the Department of General Statistics, research centers and any other related institutions.

\section{References}

Abaido, G. M. (2020). Cyberbullying on social media platforms among university students in the United Arab Emirates. International Journal of Adolescence and Youth, 25(1), 407-420.Almakanin, H. A., Younis, N. A., \& Alhiary, G. M. (2018). Electronic Bullying among a Sample of Students with Emotional and Behavioral Disorders in Zarqa City. Journal of Educational and Psychological Studies, 12(1), 179-197. http://dx.doi.org/10.24200

Alomosh, A. F., Alrahoomi, S. M., Alshamsi, M. M. H., \& Alani, O. D. S. (2019). Bullying Among School Students in the UAE Society. Psychology, 9(2), 45-56.

Becker, P., \& Wetzell, R. F. (Eds.). (2006). Criminals and their scientists: The history of criminology in international perspective. Cambridge University Press. https://doi.org/10.1017/cbo9781139052405 
Brochu, M. R. (2017). Cyber bullying: A quantitative study on the perceptions and experiences of female Emirati University students. Retrieved from http://nsuworks.nova.edu/shss-dcar-etd, last accessed on $29^{\text {th }}$ July 2020 .

Buffy, F \& Dianne, O. (2009). Cyberbullying: A literature Review. Paper presented at the Annual Meeting of the Louisiana Education Research Association Lafayette.

Fegenbush, B. S., \& Olivier, D. F. (2009, March). Cyberbullying: A literature review. In Annual Meeting of the Louisiana Education Research Association, Lafayette. Retrieved from http://www.researchgate.net/publication/228882004, last accessed on $15^{\text {th }}$ August 2020.

Homer, H. (2006). The effect of social factors on juvenile delinquency, a field study conducted in the two juvenile centers in the cities of Constantine and Ain Melilla. Algeria: Unpublished master's thesis in sociology.

Kline, P. (2013). Fact and Fantasy in Freudian Theory (RLE: Freud). Routledge. https://doi.org/10.4324/9781315871509

Lenhart, A., Madden, M., Macgill, A. R., \& Smith, A. W. (2007). Teens and social media: The use of social media gains a greater foothold in teen life as they embrace the conversational nature of interactive online media. Washington, DC: Pew Internet \& American Life Project. Retrieved from http://www.pewinternet.org/202-419-4500, last accessed on $9^{\text {th }}$ August 2020.

Lowry, P. B., Zhang, J., Wang, C., \& Siponen, M. (2016). Why do adults engage in cyberbullying on social media? An integration of online disinhibition and deindividuation effects with the social structure and social learning model. Information Systems Research, 27(4), 962-986. https://doi.org/10.1287/isre.2016.0671

Mastur, R., Al-Tkhayneh, K. \& Al-Shams, W. (2020). The Factors of Cyberbullying among the Basic Stage Students in the City of Al-Ain: A study on a Sample of Parents in The City of Al-Ain. International Journal of Innovation, Creativity and Change, 11(5). https://doi.org/10.13140/RG.2.2.31245.90084.

Ortega-Baron, J., Buelga, S., Cava, M. J., \& Torralba, E. (2017). School violence and attitude toward authority of student perpetrators of cyberbullying. Revista de Psicodidáctica (English ed.), 22(1), 23-28. https://doi.org/10.1387/RevPsicodidact.16398 
Schneider, S. K., O'donnell, L., Stueve, A., \& Coulter, R. W. (2012). Cyberbullying, school bullying, and psychological distress: A regional census of high school students. American journal of public health, 102(1), 171-177. http://doi.org/10.2105/AJPH.2011.300308

Skitka, L. J., Piatt, A. L., Ketterson, T. U., \& Searight, H. R. (1993). Offense classification and social facilitation in juvenile delinquency. Social Behavior and Personality: an international journal, 21(4), 339-346. https://doi.org/10.2224/sbp.1993.21.4.339

Sutherland, E. H., Cressey, D. R., \& Luckenbill, D. F. (1992). Principles of criminology. Altamira Press. https://doi.org/10.2307/2092772

The United Arab Emirates Government portal. (2020). Cyber safety and digital security'. Retrieved from https://u.ae/en/information-andservices/justice-safety-and-the-law/cyber-safety-and-digital-security, last accessed on $10^{\text {th }}$ Dec 2020.

Trolley, B., Hanel, C., \& Shields, L. L. (2006). Demystifying and deescalating cyber bullying in the schools: A resource guide for counselors, educators and parents. Booklocker. com, Incorporated. Retrieved from http://www.booklocker.com/p/books/2631.html?s=pdf, last accessed on 19th Sep 2020. 
